\title{
AS STARTUPS NA PERSPECTIVA DAS CADEIAS GLOBAIS DE VALOR: financeirização dos trabalhos de inovação e a reinvenção do salário por peça ${ }^{1}$
}

\author{
STARTUPS FROM A GLOBAL VALUE CHAINS PERSPECTIVE: \\ financialization of innovation work and the reinvention of piecework wage
}

Simone Wolff

\begin{abstract}
Resumo
A proposta deste artigo é contribuir com o debate acerca das formas ocultas de assalariamento decorrentes da financeirização da produção, a partir da abordagem de Cadeias Globais de Valor (CGV). Esta abordagem mira os novos expedientes de externalização das atividades produtivas das empresas transnacionais oportunizados pela desregulamentação financeira. A pesquisa circunscreve-se à deslocalização dos trabalhos de inovação através de novas modalidades de aplicações financeiras direcionadas a microempresas inovadoras, tomando como objeto as startups de base tecnológica, nas quais esses investimentos têm sido mais atuantes. O objetivo foi evidenciar que tal expediente denota um novo tipo de assalariamento por peça, assinalado pela produção sob encomenda (just in time), e impulsionado pelo capital financeiro. No caso, a peça é circunstanciada nos projetos encomendados para atender à incrementação da produtividade das empresas líderes das CGV e, com isso, a rentabilidade de seus acionistas. O instrumento mais utilizado para captar esses investimentos são os Editais de Inovação agenciados por políticas de governança e empreendedorismo, cujo principal pilar são as parcerias público-privadas. A análise de dois editais dessa natureza permitiu constatar que esses atuam como um meio de conectar encomendas corporativas a trabalhadores autônomos, servindo como um artifício para disfarçar processos de terceirização dos laboratórios de inovação das grandes marcas e disponibilizar força de trabalho qualificada sem despesas trabalhistas. Assim, riscos e custos laborais são transferidos às startups proponentes, ao mesmo tempo em que as deixa permanentemente disponíveis para novos pedidos, reiterando o paradigma do trabalho intermitente e sem direitos, característico do capitalismo contemporâneo.

Palavras-chave: Cadeias globais de valor. Startups. Financeirização da produção. Salário por peça.
\end{abstract}

\begin{abstract}
This study aims to contribute to the debate about the reinvention of piecework due to financialization of production, from a Global Value Chains (GVC) perspective. From this angle, new putting-out strategies of production activities facilitated by financial deregulation of transnational corporations became clear. The research about dislocated innovative work through new financial investments directed to innovative small firms has as subject startups of technological basis in which such investments have been more active. The putting-out system thus reveals the reinvention of piecework marked by just in time production and promoted by the financial capital. In this context, piecework is based on projects to attend productivity demands and profitability of leading companies of GVC, thus the rise of profitability for shareholders. Innovation Notices (Editais de Inovação) under a governance paradigm, entrepreneurship politics and public-private partnership are the most common type of such investments. The analysis of two notices demonstrate that they connect corporate demands to autonomous workers, thus reinventing outsourcing practices in innovation centers and making available a qualified and informal workforce. Therefore, the classical paradigm of temporary and informal work in contemporary capitalism is reinforced as risks and labor costs are shifted to startups, making workers permanently available.
\end{abstract}

Keywords: Global value chains. Startups. Production financialization. Workpiece wage.

1 Agradeço aos pareceristas da revista pelos comentários precisos e aos e às participantes do Grupo de Estudos sobre Novas Tecnologias e Trabalho (GENTT) pelas ricas discussões e pelo apoio técnico que propiciaram à pesquisa. " Professora Associada do Departamento de Ciências Sociais e do Programa de Pós-Graduação em Sociologia da Universidades Estadual de Londrina - UEL. Doutora em Ciências Sociais pela UNICAMP. Líder do Grupo de Estudos sobre Novas Tecnologias e Trabalho - GENTT. E-mail: wolff.simone@gmail.com 


\section{Introdução}

As cadeias globais de valor (CGV) são a última expressão do padrão de expansão e reprodução ampliada do capital, após quatro décadas de liberalização econômica em escala mundial. Essa abordagem permite observar como a liberdade financeira permitiu às grandes empresas reestruturar suas cadeias produtivas por meio de investimentos em negócios juridicamente autônomos e potencialmente rentáveis ao incremento e diversificação de seus empreendimentos, estabelecendo um regime de acumulação excepcionalmente condicionado ao capital financeiro (CHESNAIS, 2013; GUTTMANN, 2008). Essas transações são mormente direcionadas às atividades comerciais e logísticas dos produtos das grandes empresas globais nos espaços nacionais.

A proposta deste artigo é se valer de uma análise crítica das CGVs como recurso metodológico para revelar os novos expedientes de externalização dos laboratórios de inovação das grandes empresas, efetivados via capital financeiro, que ocultam um novo assalariamento por peça demarcado pela produção sob demanda (just in time). No caso, a peça é representada pelos projetos temporários encomendados para oportunizar novos negócios lucrativos, com custos e riscos compartilhados com os seus proponentes. Tal análise mira o padrão de industrialização calcado na dominância financeira que permite reduzir custos de transação e produção transferindo riscos para terceiros, concomitante à apropriação de lucros sob a forma de renda a partir de um conjunto de ativos financeiros que, de fato, é o que sustenta e controla esses projetos (SCHERER, 2014). São esses investimentos que conectam as demandas das grandes corporações às operações necessárias para levar seus produtos e serviços até mercados finais cada vez mais longínquos.

Uma das principais políticas para a captação desses ativos é a abertura a novas modalidades de aplicações financeiras voltadas para microempresas nascentes, que envolvem menores aportes de capital, porém com maior risco quanto às garantias de retorno lucrativo (SPOSITO; SANTOS, 2012). Essa modalidade de microempresa é chamada de startup de base tecnológica e tem como escopo produzir projetos que visam a inovações passíveis de se tornarem escaláveis, característica considerada fundamental para atrair esses investimentos por ter maior garantia de mercado, já que seus resultados podem ser replicados sem acarretar grandes aquisições (BICUDO, 2016).

O instrumento mais utilizado para esse fim são os Editais de Inovação lançados por agências de fomento ao sistema produtivo nacional, dentro do chamado modelo de governança, cujos principais pilares são as parcerias público-privadas. Juntamente às políticas de empreendedorismo, a governança vem sendo perfilhada como uma estratégia basilar de desenvolvimento capaz de alavancar a inserção qualificada do país na economia internacional (WOLFF, 2019; SANTOS; KREIN; CALIXTRE, 2012). A perspectiva aqui adotada se contrapõe a essa visão ao compreender tais editais como um método de agenciamento de força de trabalho 
qualificada barata para as empresas que encabeçam as CGVs, e/ou para aumentar a lógica dos mercados de capitais por essas patrocinados, que não se comprometem como países, mas apenas com rentabilidade.

Para fundamentar esse argumento, foram selecionados dois editais voltados ao fomento de startups, visando evidenciá-las como um modelo de negócios representativo do atual regime de acumulação sob predominância financeira e do novo salário por peça que este assinala. Além desta introdução e das considerações finais, o percurso conta com mais três seções. $\mathrm{Na}$ primeira, será apresentada a relevância que as microempresas ganharam no contexto das CGVs em conjunto com as políticas que visam promover a sua inserção nessas cadeias e que orientam as startups em tela. Essa discussão servirá de base para a problematização do assalariamento por peça ensejado pela financeirização da produção, que será realizada na segunda seção. A terceira analisa os editais à luz da metodologia construída nas seções anteriores, a fim de revelar os vínculos intermitentes de emprego incentivados pelas políticas de governança e empreendedorismo inovador.

\section{Terceirização disfarçada: as microempresas no contexto das CGVs}

As cadeias globais de valor (CGV) dizem respeito à transferência de toda a gama de atividades envolvidas para a fabricação e venda de um dado produto para fora dos países que sediam as empresas proprietárias da sua marca e patentes de produção (GEREFFI, 1999). Desde a abertura das economias nacionais, essas externalizações são mobilizadas via investimentos financeiros que reestruturaram as cadeias produtivas das grandes empresas de dois modos interrelacionados: 1. as cadeias produtivas dirigidas pelo produtor, quando uma grande indústria detém e controla a maior parte das operações a montante e a jusante do seu produto final, formando oligopólios e ditando o consumo; e 2. as cadeias produtivas dirigidas pelo comprador, quando uma grande marca coordena todas as etapas do processo até a chegada ao consumidor final, sendo ditada pelo consumo (GEREFFI, 1999). Enquanto a primeira é liderada pelo capital industrial, a segunda é puxada pelo capital comercial, sendo o capital financeiro liberalizado o elo que conecta ambos mediante duas formas de investimento que perfazem as CGVs: os Investimentos Estrangeiros Diretos (IED) e as Novas Formas de Investimentos (NFI).

O IED visa o controle acionário, total ou parcial, de empresas nacionais mediante privatizações e fusões com empresas estrangeiras. Geralmente, esse tipo de investimento se dirige às indústrias de grande porte que possuem maior potencial de internalização de oligopólios globais, como é o caso das corporações inseridas nas cadeias produtivas de tipo 1 (SANT ANNA, 2017). Já as NFIs referem-se ao controle de firmas nativas por corporações estrangeiras através de processos de externalização que prescindem de propriedade direta, tais como acordos de licença de uso e de assistência técnica, franquias, terceirizações e subcontratações internacionais etc. 
(SPOSITO; SANTOS, 2012; MARTINEZ-ORTIZ, 1994). Esse gênero de investimento prevalece nas cadeias produtivas de tipo 2, responsáveis por escoar os produtos das cadeias de tipo 1.

As NFIs foram particularmente favorecidas pela desregulamentação financeira, a partir da qual se originou uma ampla variedade de novos ativos monetários intangíveis que aumentou o leque de oportunidades de investimentos lucrativos, dispensando gastos com grandes aquisições. É essa cartela de produtos financeiros que constitui o coração das CGVs de tipo 2. Seus fluxos reconfiguraram o padrão de internacionalização do grande capital, tanto setorialmente, em vista da transferência de operações produtivas, logísticas e varejistas para firmas de outros países, como funcionalmente, ao envolver atividades de pesquisa e desenvolvimento $(P \& D)$ direcionadas à incrementação e parametrização desses processos, de acordo com as especificidades legislativas e de consumo das regiões em que se insere (SCHERER, 2014).

Essa industrialização puxada pelas finanças ocasionou uma interação estreita entre empresas financeiras e não financeiras, de tal modo que se tornou difícil discernir suas fronteiras (SERFATI, 2008). Tal amálgama levou as empresas que lideram as CGVs a se constituírem como fábricas sem fábricas, visto que se restringem à propriedade de marcas e patentes enquanto seus produtos e serviços passaram a ser produzidos em diferentes pontos do planeta (COWEN, 2014). São essas duas propriedades que sustentam toda a cadeia produtiva dessas empresas, reduzindo a sua estrutura a um sistema informacional virtual que integra e administra as suas redes globais de produção e circulação. Com efeito, é muito mais vantajoso transferir essas atividades para firmas locais menores do que edificar estruturas próprias e, portanto, sujeitas a tributos.

Devido à intensa fragmentação e dispersão geográfica que esse movimento implica, um ambiente institucional confiável e apto ao aprovisionamento dos fatores necessários à gestão e operação desses processos torna-se decisivo para a motivação e permanência desse capital circulante. Essa conjuntura tem levado os países com um sistema produtivo de baixa densidade tecnológica a apostar na abertura a esse tipo de capital como um meio de absorver tecnologia de ponta e, assim, ampliar a oferta de produtos de maior valor agregado no âmbito do comércio exterior. Tal expectativa vem reorientando as políticas de desenvolvimento nacional no sentido de tornar seus sistemas produtivos mais atrativos às NFIs.

Uma das ações centrais para colocar a economia nacional no itinerário desses investimentos é o estabelecimento de acordos de cooperação em $\mathrm{P} \& \mathrm{D}$ que possam propulsar a sua inserção nas CGVs. As empresas que lideram essas cadeias, por sua vez, veem nessas parcerias oportunidades de promover inovações que concorram para expandir o consumo de suas marcas e patentes, se valendo de recursos localmente disponíveis para baratear custos (FAUSTINO; GOHR, 2016). Em tal contexto, as rendas relacionais, ou seja, ações institucionais capazes de conectar grandes empresas a pequenas firmas locais, ganham especial importância para o agenciamento dessas parcerias (OLAVE; AMATO NETO, 2001).

É dentro desse quadro que a internacionalização das micro e pequenas empresas (MPE) adquirem um papel estratégico. Conforme o Serviço Brasileiro de Apoio às Micro e Pequenas 
Empresas (SEBRAE, 2006, p. 12), a MPE pode representar uma parceria interessante para as empresas globais por "oferecer produção flexível, algo bastante atrativo para indústrias com demanda ou oferta sazonal; possíveis reduções de custo de produção em indústrias intensivas em trabalho; e proximidade com os mercados". O caminho para tanto seria se tornar "um fornecedor para grandes empresas internacionais e concorrer por preço ou se especializar em nichos de mercados" (SEBRAE, 2006, loc. cit.).

Com a retração do papel do Estado na economia, essas transações passaram a ser afiançadas pelo chamado modelo de governança, que se alicerça nas parcerias público-privadas (PPP). Aplicada aos sistemas produtivos de inovação, a governança tem o objetivo de criar mecanismos institucionais de apoio a investidores, tendo no "empreendedorismo inovador" um de seus principais instrumentos (OLIVEIRA; CARNEIRO; SILVA FILHO, 2017; CONCEIÇÃO; FEIX, 2014). Essa concepção de empreendedorismo postula um novo perfil de MPE definido como toda atividade que "se dedica à geração de riquezas, seja na transformação de conhecimentos em produtos ou serviços, na geração do próprio conhecimento ou na inovação em áreas como: marketing, produção, organização, etc." (LOURES, 2015, p. 93).

Portanto diferente do empreendedorismo compensatório à parcela de trabalhadores não absorvida no seguimento industrial, a MPE inovadora se anexa à indústria (NARETTO; BOTELHO; MENDONÇA, 2004). Isso porque se configura como um meio para acelerar a transição de uma economia movida por fatores de produção, caracterizada pelo predomínio de commodities e de produtos de baixo valor agregado, para o "estágio movido pela inovação", capaz de criar as condições para qualificar pequenos negócios locais na rota mercantil e financeira das CGVs (OLIVEIRA; CARNEIRO; SILVA FILHO, 2017). Com isso, espera-se criar negócios mais competitivos para alavancar a economia nacional e gerar ocupações mais bem qualificadas e remuneradas (OLIVEIRA; CARNEIRO; SILVA FILHO, 2017).

Contudo, na medida em que as MPEs se colocam como fornecedoras das grandes empresas, suas atividades tendem a se confinar às franjas de suas cadeias produtivas, onde estão os processos de menor valor agregado quando comparados àqueles responsáveis por alterar padrões de consumo (WOLFF, 2019). Desse modo, longe de concorrerem para alçar a economia nacional a exportadoras de tecnologias avançadas, as atividades geradas dentro deste quadro são extremamente dependentes dos parâmetros tecnológicos das empresas globais (KREIN; BIAVASCHI, 2012). Deste prisma, o empreendedorismo inovador se revela como um mecanismo de terceirização disfarçada pelo recurso à "pejotização" do trabalho, que se refere à prática de camuflar vínculos empregatícios mediante a substituição da carteira de trabalho por contratações via Pessoa Jurídica (KREIN, 2018).

Nesse enfoque, as MPEs atuam como "empresas-mão" financeiramente subordinadas às "empresas-cabeça" das CGVs (CASTILLO, 2008), em especial as de tipo 2, que são as que se valem das NFIs para promover seus processos de externalização. Essa subordinação é dissimulada não somente pela aparência de negócios juridicamente autônomos, mas também 
pelas políticas de governança e empreendedorismo inovador, que organizam esses vínculos de forma contingente por meio do agenciamento de parcerias firmadas sobre projetos específicos e temporários voltados à incrementação de processos e produtos das grandes companhias.

É desde essa aparente autonomia que essas inovações deixam de representar custos de produção para se tornarem etapas de agregação de valor a essas funções, já que fora das grandes empresas essas se convertem em postos de trabalho produtivo (HUWS et al., 2009), com a vantagem adicional de que as tributações relativas a esses custos também são externalizadas. Considerando que as MPEs representam hoje 99,1\% do total de empresas registradas no Brasil, respondendo por 52,2\% dos empregos de carteira assinada (DATASEBRAE, 2019), depreende-se que a grande indústria não se rarefez, antes se encontra pulverizada de forma ubíqua nas MPEs que, sob a regência do capital financeiro, passam a participar ativamente dos seus processos globais de valorização.

A problematização feita em torno das MPEs inovadoras possibilitou constatar que essas serviram como um modelo precursor das startups de base tecnológica, que será visto a seguir. A análise procurará demonstrar como essa nova modalidade de microempresa aprofundou a subsunção dos serviços de inovação à lógica do regime de acumulação dominado pelas finanças emanado das CGVs de tipo 2, baseadas nas NFIs.

\section{As startups na perspectiva das cadeias globais de valor: subsunção financeira e o novo salário por peça}

As startups de base tecnológica, também chamadas de inovadoras, são um tipo de microempresa conceituada como nascente, com até cinco anos de existência, e destinada à captação de recursos para o desenvolvimento de produtos replicáveis e escaláveis a partir de projetos selecionados por tempo determinado (BICUDO, 2016). Por ser um negócio eminentemente financeirizado, as startups inovadoras se distinguem como o perfil de microempresa mais afeito ao tipo de investimento carreado pelas NFIs que, neste contexto, se estabelecem por joint venture. Esse gênero de financiamento é realizado por meio de alianças corporativas de curto prazo, inclusive abertas ao capital estrangeiro e firmadas em torno de um projeto comercial comum envolvido nos vários níveis da cadeia de um produto, compartilhando lucros e prejuízos quanto aos seus resultados. Dada a imprevisibilidade desses resultados, o joint venture é considerado um investimento de risco (VILELA; SANTOS JHUNIOR, 2018).

Em vista da sua aptidão para atrair investimentos estrangeiros, as startups inovadoras vêm sendo objeto de várias ações de incentivo no Brasil, tanto públicas como privadas, que atuam sob o modelo de governança com a finalidade de criar um ambiente propício à captação desses recursos (NICOLAS; PIQUÉ, 2016). No âmbito governamental, destacam-se os programas Start-Up Brasil (2012), vinculado ao Ministério da Ciência, Tecnologia, Inovações e Comunicações (MCTIC); InovAtiva Brasil (2013), Inovapps (2014), promovidos pelo Ministério 
da Economia, Indústria, Comércio Exterior e Serviços (MDIC); bem como as várias incubadoras, normalmente acolhidas em universidades públicas, e os parques tecnológicos promovidos por políticas municipais (RONCARATTI, 2017).

Essas iniciativas têm a finalidade de promover o que no léxico empresarial é chamado de “ecossistemas de inovação", concebidos como um ambiente favorável à articulação das políticas de apoio aos sistemas produtivos nacionais a mecanismos de geração de empreendedorismo inovador (AUDY; PIQUÉ, 2016). As chamadas aceleradoras têm desempenhado um importante papel para a constituição desses ecossistemas, pois são um tipo de incubadora especializada na propulsão de parcerias baseadas em joint ventures. A institucionalização dessas relações ocorre pela intermediação de editais voltados ao fomento de startups de base tecnológica.

Como visto, essa produção monetizada definiu uma divisão internacional da produção multiforme e fragmentada, em virtude da incorporação dos serviços como fator-chave de agregação de valor e, ainda, da importante participação do comércio de componentes como indicativo de maior integração internacional dos países (SCHERER, 2014). Tal cenário induziu à criação de uma legislação específica para as startups que até recentemente, eram regidas pelo Estatuto Nacional da Microempresa e da Empresa de Pequeno Porte, instituído em dezembro de 2006 pela Lei 123, em complemento à lei 9.613 de março de 1998 que fundou o Conselho de Controle de Atividades Financeiras - COAF. A lei 123/2006 representou um grande incentivo às empresas desse porte ao instituir o Simples Nacional, que isentou as MPEs de todos os impostos federais por dois anos, podendo ser prorrogáveis por mais dois e passando a ser de $50 \%$ por ano após esse período.

Apenas em abril de 2019, pela Lei 167, as startups passaram a receber um tratamento diferenciado relativamente às MPEs, através do Inova Simples, que substituiu o Simples Nacional por um sistema automático exclusivo para o seu registro e legalização tornando esses procedimentos mais ágeis, mantendo os mesmos incentivos tributários. Essa lei também trouxe uma definição mais precisa de startup, descrita como uma microempresa de "caráter inovador" com o objetivo de "aperfeiçoar sistemas, métodos ou modelos de negócio, de produção, de serviços ou de produtos" em "condições de incerteza" (CÂMARA DOS DEPUTADOS, 2019). Nos termos da lei, as startups podem ser de "natureza incremental", quando visam a inovação de produtos já existentes, ou de "natureza disruptiva", quando tem como escopo "a criação de algo totalmente novo".

As startups que se ocupam com inovações incrementais são conhecidas como copycat, ou de imitação, visto que não tencionam alterar padrões de consumo, mas customizar tecnologias já consolidadas no mercado. Do ponto de vista dos investidores, as inovações incrementais têm maiores chances de resultar em produtos escaláveis sem que sejam necessárias muitas adaptações e, portanto, custos, compensando os investimentos de risco por uma maior garantia de venda para grandes mercados (ISHIZAKA; LIZARELLI, 2016). Vários estudos demonstram que nos países periféricos prevalecem as startups copycat, sendo as de natureza disruptiva 
mais presentes em países de industrialização avançada (RONCARATTI, 2017). Tal fenômeno também é explicado pela falta de oportunidade de empregos formais qualificados nos países de baixa industrialização (RONCARATTI, op. cit.).

A prevalência das startups copycat nesses países também indica que o regime de acumulação dominado pelas finanças agravou a dependência dos seus sistemas produtivos às patentes tecnológicas estrangeiras (CHESNAIS, 2013; SPOSITO; SANTOS, 2012). Além disso, o incentivo às startups tem funcionado como uma estratégia para absorver a força de trabalho qualificada expulsa da grande indústria pelos processos de externalização dos seus laboratórios de $P \& D$ na forma de um novo salário por peça, representado pelos projetos de inovação capitaneados pelas CGVs. Isso porque, em termos organizacionais, essas cadeias se estruturam conforme os métodos toyotistas de produção enxuta, que eliminaram os grandes estoques por técnicas logísticas voltadas à produção sob encomenda (just-in-time) (COWEN, 2014). No caso, essas encomendas são acionadas através das NFIs oriundas das CGVs de tipo 2, que buscam lucrar com ideias que possam agregar valor a tecnologias já estabelecidas e, por conseguinte, com maiores chances de se concretizarem em produtos escaláveis.

Tal como o que ocorre com as MPEs inovadoras, a força de trabalho demandada para esses processos tem sido realocada nas startups por meio de vínculos casuais de emprego urdidos pelo capital financeiro. A sua conexão ao arcabouço diversificado de negócios e ativos monetários implicados nas CGVs de tipo 2 é plugada a partir do financiamento de projetos com objetivos e tempo predefinidos, sendo os editais voltados para o seu fomento um dos principais instrumentos para esse fim. É essa economia por conexão que levou ao ressurgimento do salário por peça, aqui retratado pelos projetos submetidos a esses editais.

O salário por peça foi a primeira forma de assalariamento e caracterizou o modelo mercantilista que deu origem ao capitalismo, o qual era igualmente dependente do capital monetário para poder se expandir (MARX, 1984). Marx (1984) postulou essa forma de assalariamento como aquela que melhor responde ao anseio do capital de aliar o controle do trabalho com baixos custos de produção, uma vez que esse tipo de remuneração emula os trabalhadores a produzirem mais rapidamente, sem limitações legais quanto à jornada de trabalho, ao mesmo tempo que reduz despesas salariais com deslocamentos.

A grande indústria foi gestada dentro desse sistema externalizado de fabricação, especificado como putting-out-system. Em um período marcado pelo sistema colonial, e pela ausência da grande indústria, o sucesso do capitalista passava pelo acesso rápido aos locais onde havia insumos baratos e força de trabalho capacitada para a sua manufatura. Nesse sistema de produção, o capitalista se consubstanciava na figura do negociante, pois seus lucros procediam da sua vantagem de circulação, que lhe oportunizava a compra de matérias-primas e produtos finais de mercados mais baratos para a sua venda em mercados mais caros.

A atual liberalização do trânsito de capital entre países restabeleceu essa capacidade de circulação favorecendo um novo feitio de putting-out-system. A diferença em relação ao 
negociante dos primórdios do capitalismo é que agora esse tráfico ocorre em escala planetária, pois foi otimizado pelo advento das Tecnologias de Informação e Comunicação (TIC). Essas tecnologias proporcionaram a esse capital circulante o poder de fluir mundo afora em busca da apropriação de conhecimentos aptos a servirem de matérias-primas passíveis de agregar valor aos seus meios de produção, que também são desenvolvidos sobre suas plataformas. Essa acumulação via circulação desenhou uma estrutura de grande indústria diminuta, circunscrita às funções estratégicas para a manutenção do seu domínio sobre o mercado mundial, tais como produção de patentes, diversificação e gestão financeira de seus negócios.

Neste contexto, as empresas globais passam a se definir como conectoras e organizadoras dos fluxos globais de capital industrial e comercial através do controle do capital acionário, borrando as barreiras entre finanças e indústrias (CASSIOLATO, 2013). Todas as demais atividades passíveis de resultarem em novos insumos que possam agregar valor e ampliar o consumo das suas marcas são externalizadas, de maneira a convertê-las em negócios com potencial de auferir lucros futuros. Deste modo, denotam-se como fábricas sem fábrica, pois não se organizam mais com base em uma grande planta industrial e sim por meio de uma logística virtual pulverizada e financeirizada, que torna o mundo inteiro lócus de valorização (PRADO, 2005).

O modus operandi deste novo putting-out-system se caracteriza pela modularização da produção, processo pelo qual componentes com novas funções podem ser encaixados à uma dada base tecnológica sem alterar a sua arquitetura (MORO; MIGUEL, 2016). Este recurso reconfigurou o princípio da inovação, permitindo promover melhorias de desempenho, automação e redução de custos operacionais nos vários níveis de uma cadeia produtiva a partir de um mesmo sistema, abrangendo desde o desenvolvimento e diversificação de produtos e serviços até a sua integração aos processos logísticos de transporte, armazenamento e comercialização (COWEN, 2014).

A modularização da produção possibilitou externalizar essas operações e recontratálas sob a forma de fornecedores de serviços eventuais, remunerados de acordo com demandas sazonais. O que distingue esse tipo de externalização com a primeira forma de putting-out-system é que agora, além de se apropriar das matérias-primas, controlar sua distribuição, e determinar o projeto e prazo de entrega, a grande indústria também detém o design das ferramentas de trabalho. Com isso, consegue englobar processos produtivos que ocorrem fora dos seus muros, além de ter sempre disponível uma força de trabalho habilitada para o uso dessas ferramentas, que pode ser recrutada, em qualquer tempo e lugar, através dos investimentos financeiros diretos beneficiados pelo livre mercado.

O trabalho de inovação é um campo, particularmente, profícuo para compreender esse sistema de fábrica pulverizada por meio da financeirização da produção, e o novo salário por peça que este demarca, visto que é onde o controle do capital financeiro tem sido mais atuante. Isso porque é a atividade responsável pelo desenvolvimento das adaptações necessárias para o ajuste dos produtos das empresas globais aos padrões de consumo e legislativos dos mercados 
que abarcam. Por isso, sua análise permite perceber como esses processos se concretizam nos sistemas produtivos nacionais e determinam seus mercados de trabalho.

Neste aspecto, os editais de fomento às startups podem ser entendidos como uma dessas práticas, visto que servem como um meio de conectar as demandas dos investidores com a força de trabalho capacitada para o desenvolvimento de projetos com viabilidade de ampliar os mercados das patentes tecnológicas das transnacionais. Ocorre que as redes emaranhadas e descontínuas de arranjos institucionais, parcerias e fontes de financiamento que se urdem sob esses editais obscurecem a subordinação dessas startups relativamente a quem vai se apropriar dos resultados dos seus projetos. A apreciação dos editais, a seguir, procurará desembaraçar essas relações, no intuito de desvendá-las como uma forma de assalariamento por peça subordinada às dinâmicas das CGVs.

\section{Os editais:}

\section{de âncora à semente, salário intermitente}

Os editais de fomento às startups de base tecnológica são um tipo de aliança estratégica entre empresas característica da economia conectiva delineada pelas NFIs problematizadas na seção anterior, servindo como um meio de conexão entre grandes e pequenas empresas. Essa estratégia tem o propósito de "atacar mercados precisos com o objetivo de se apossarem de partes de mercados em detrimento de concorrentes que se encontram em desvantagem face às empresas ligadas por alianças estratégicas" (OLAVE; AMATO NETO, 2001, p. 292). Tais acordos atuam pela prática de cross fertilization, que se refere ao uso de ideias provenientes de diversos lugares e grupos, a fim de produzir resultados diferenciais no mercado.

Dentre os vários tipos de alianças entre empresas, aquela que melhor se ajusta aos editais em questão é a aliança oportunística. Os investimentos derivados desse tipo de acordo são feitos visando desenvolver inovações incrementais para grandes empresas mediante aportes em startups de base tecnológica. O objetivo é oportunizar vantagens competitivas que possam ampliar os seus negócios ou criar novos empreendimentos. Essas alianças se firmam como "parcerias de distribuição", definidas como aquelas em que "produtores dividem custos de estrutura física e humana para armazenamento e distribuição do produto no mercado comprador" (SEBRAE, 2006, p. 124). Por isso, possuem um nível de comprometimento médio com o mercado internacional, já que seus produtos objetivam atender mercados internos.

Nesse caso, a internacionalização acontece quando o foco se volta para a melhoria do acesso entre firmas locais aos canais de distribuição de empresas estrangeiras que pretendem entrar em mercados nacionais (SEBRAE, 2006). Esse tipo de parceria opera por joint venture, firmada pelo interposto de editais de fomento à MPEs e às startups inovadoras. Sendo assim, os editais dessa natureza institucionalizam um sistema de fábrica virtual e ocasional, dentro do modelo de putting-out-system característico das CGVs de tipo 2. 
Na perspectiva aqui adotada, pode-se dizer que essa intermediação viabiliza a conexão entre um patrão intermitente (os investidores) e a força de trabalho subordinada às suas demandas mercadológicas presente nas startups. Neste sentido, tais editais desempenham um papel de negociante just in time de força de trabalho qualificada para o manuseio das tecnologias necessárias para abrir ou ampliar mercados, bem como desenvolver ou aprimorar a logística necessária para o seu comércio nos territórios nacionais. Para esta análise, foram selecionados dois editais. No primeiro, a demanda parte diretamente da indústria, visando à melhoria da produtividade de processos, produtos e serviços. No segundo, procede de investidores aleatórios privados visando a incentivar ideias temáticas que possam resultar em inovações modulares vocacionadas para customizar a integralização de componentes de fábricas inteligentes, isto é, baseadas em serviços de internet.

\section{Edital SI}

O Edital de Inovação para a Indústria (Edital SI) foi proposto pelo Sistema de Indústria (Sebrae, Sesi, Senai) e lançado em maio de 2018. O objetivo foi "financiar o desenvolvimento de soluções inovadoras para a indústria brasileira, sejam elas novos produtos, processos ou serviços de caráter inovador" com vistas a promover "o aumento da produtividade e competitividade industrial brasileira", através do financiamento de horas técnicas, matéria-prima e insumos (SEBRAE; SESI; SENAI, 2018, p. 2).

Nos termos do edital, os projetos de inovação, referidos como "ideias", são aqueles que propõem "soluções a desafios tecnológicos, em estágio que demande desenvolvimento ou aprimoramento tecnológico para realização de prova de conceito, preparação de planta piloto ou ainda para inserção da solução no mercado" (SEBRAE; SESI; SENAI, 2018, p. 4). Dentre os temas da chamada, destacam-se: A. Inovação Tecnológica para Grandes e Médias Empresas, B. Inovação Tecnológica para Micro e Pequenas Empresas (MPE), Microempreendedor Individual (MEI) e Startups de Base Tecnológica, e C. Empreendedorismo Industrial - Grandes empresas e Startups.

As startups, denominadas como Empresas Proponentes (EP), foram descritas como empresas nascentes com faturamento anual inferior a 4,8 milhões de reais (MEI ou MPE), com Cadastro Nacional de Pessoa Jurídica (CNPJ) e até cinco anos de existência. As empresas investidoras, referidas como Instituições Âncoras (IA), foram designadas como empresas de médio e grande porte com comprometimento de "disponibilizar recursos próprios para apoiar a execução de projetos de inovação" voltados a "temas específicos de seu interesse" (SEBRAE; SESI; SENAI, 2018, p. 2). O edital ainda abriu possibilidade de se estabelecer parcerias com centros de pesquisa e instituições estrangeiras, sendo que "todos os envolvidos compartilharão conjuntamente as obrigações e riscos do projeto" (SEBRAE; SESI; SENAI, 2018, p. 3).

Com exceção das inscrições submetidas à linha de tecnologias educacionais, que contaram com orçamento e prazo diferenciados, a duração dos projetos foi estipulada em até 24 meses, 
sem possibilidade de prorrogação. O valor máximo previsto para cada projeto foi de 400 mil reais sendo $75 \%$ desse valor contrapartida financeira do edital e $25 \%$ dos Departamentos Regionais (DR) do Senai envolvidos nos respectivos planos de trabalho. Para a grande empresa investidora, a contrapartida obrigatória foi de $50 \%$ e para a média empresa de $25 \%$ do valor do projeto selecionado. Às EPs, a contraparte fixada foi de $10 \%$ do valor previsto no projeto, com opção de aporte de mais $10 \%$ para alcançar a pontuação máxima classificatória. Ao Sebrae ficou a responsabilidade de viabilizar o acesso das startups à infraestrutura e conhecimentos científico-tecnológicos dos Institutos Senai de Inovação (ISI) e Institutos Senai de Tecnologia (IST).

As IAs tiveram a prerrogativa de "definir as condições de participação no projeto, podendo ser participação acionária na Empresa Proponente, Royalties ou outros", com "total autonomia para selecionar as EPs em todas as fases da chamada podendo, inclusive, optar por não selecionar nenhuma" (SEBRAE; SESI; SENAI, 2018, p. 37). A IAs, portanto, foram as protagonistas do edital, pois ficaram com a incumbência de realizar as "chamadas temáticas específicas, negociar e validar as regras que estabelecem os valores dos projetos", além de gerilos em conjunto com os DRs do Senai e Sesi (SEBRAE; SESI; SENAI, 2018, p.3). Evidencia-se, assim, o seu papel de patrão, já que o objetivo das EPs foi o atendimento das suas demandas de produtividade.

Cabe notar que, embora essas soluções tecnológicas sejam aplicáveis somente no plano das IAs, as EPs assumem conjuntamente os riscos dos projetos, o que revela como este modelo de negócios é vantajoso para a redução dos custos operacionais e de transação das IAs. Esses custos são subsidiados pelo Sesi e Senai, e pelas próprias EPs, o que torna os investimentos necessários à concepção e desenvolvimento de tais projetos bem mais baratos do que se tivessem que ser arcados totalmente no interior das IAs. É por este artifício que esses custos são externalizados e se convertem em etapas de agregação de valor aos seus processos.

Deste modo, o edital exerce a função de afiançar e estruturar, dentro do modelo de governança, uma usina virtual e contingente de ideias inovadoras para as IAs, nos moldes da própria da produção sob encomenda. Ademais, serve como intermediador e subsidiador de força de trabalho habilitada ao desenvolvimento dessas encomendas, a partir da sua contração just in time. No Edital SI, então, a subordinação das EPs às IAs se revela da seguinte maneira: 1) apesar de serem juridicamente autônomas, as startups selecionadas se submetem às demandas das IAs, estando, pois, a seu serviço; e 2) mesmo subordinadas às IAs, devido ao seu estatuto de Pessoa Jurídica, as EPs deixam de representar custos de produção para se tornarem etapas de agregação de valor aos seus processos e produtos.

\section{Edital FINEP}

O Edital Finep Startup - Programa de Investimento em Startups Inovadoras - foi aberto em julho de 2017 e promovido pela Financiadora de Inovação e Pesquisa (Finep). A Finep é 
uma agência pública vinculada ao MCTIC, que tem como objetivo financiar a inovação desde a pesquisa básica até a preparação do produto para o mercado. Seus recursos são oriundos do Fundo Nacional de Desenvolvimento Científico e Tecnológico (FNDCT), do Fundo para o Desenvolvimento Tecnológico das Telecomunicações (Funttel), e de convênios de cooperação com ministérios, órgãos e instituições setoriais (FINEP, 2019).

O edital teve como objetivo disponibilizar recursos a startups em sua fase inicial, considerada a mais crítica e dispendiosa, com o propósito de contribuir para a "criação de empregos qualificados e geração de renda para o País", bem como para o "crescimento do mercado de capital semente no Brasil, compartilhando com os investidores privados os riscos associados ao investimento em empresas nascentes de base tecnológica" (FINEP, 2017, p.1). Capital semente é o investimento inicial em startups, feito por indivíduos ou empresas, visando a subsidiar o desenvolvimento de inovações tecnológicas. Esse investimento é considerado de risco porque é realizado na fase de desenvolvimento dos protótipos, sem garantia de retorno. $\mathrm{O}$ edital, assim, atendeu ao incentivo do "ecossistema de inovação" no país, através da política de governança, que compartilha os riscos dos investimentos com o setor privado.

O valor total do edital foi de 50 milhões de reais, sendo até 1 milhão de reais por projeto, feito mediante duas "rodadas de investimento" correspondentes ao "valor total da captação realizada pela empresa no âmbito da proposta submetida, incluindo o valor do aporte realizado pela Finep mais o valor aportado pelos demais investidores que acompanharem o investimento" (FINEP, 2017, p. 16). A cada rodada foi prevista a seleção de até 25 startups. Os temas apoiados foram: Educação; Cidades Sustentáveis; Fintech; Internet das coisas; Economia Criativa; Energia; Defesa; Mineração; Petróleo; Manufatura avançada; Biotecnologia; Agritech; Química; BIM (Building Information Modeling) - Soluções.

Diferente do Edital SI, os recursos previstos foram repassados diretamente às startups proponentes, não tendo demandas oriundas de empresas específicas. Nesse caso, as startups se colocam como subordinadas aos investidores-anjo, pessoas físicas, nacionais ou internacionais, que aplicam o capital semente. A contrapartida dos investidores-anjo foi a participação nos retornos obtidos pelos projetos selecionados nas mesmas condições da Finep, em valor proporcional ao aportado em cada rodada de investimento. Tanto a Finep como os investidoresanjo também tiveram a opção de compra das startups selecionadas, garantida em contrato de acordo com o percentual investido por cada parte.

Para esta análise, destacam-se os seguintes critérios de elegibilidade das startups: 1 . o registro sob a forma de sociedade limitada (LTDA) ou de sociedade anônima (S/A); 2. que fossem "capazes de desenvolver produto, serviço ou processo novo a partir da integração de tecnologias existentes com adição de desenvolvimento novo"; e 3. que seus projetos estivessem "no mínimo na fase de protótipo ou testes, preferencialmente já tendo sido realizadas as primeiras vendas, não podendo encontrar-se em fase de ideia ou pesquisa" (FINEP, 2017, p. 5). Às startups que apresentassem "cartas de compromisso de investimentos" com valor superior a 50 mil reais 
anexadas ao projeto, foi prevista pontuação maior na avaliação.

Destaca-se que os negócios registrados como LTDA podem ser constituídos por apenas uma pessoa, o que caracteriza um tipo de pejotização do trabalho. Já o estatuto de S/A isenta os acionistas de qualquer responsabilidade quanto ao insucesso da empreitada, ou seja, a sua participação é restrita à propriedade das ações, o que significa que os projetos submetidos a essa forma de investimento ficam com os riscos maiores do empreendimento. Neste aspecto, é sintomático deste quadro analítico a preocupação do atual governo federal em estabelecer um marco regulatório das startups visando a "criação de incentivos fiscais para investidores e mecanismos para evitar que eles arquem com passivos no caso de falência da startup" (OLIVEIRA, 2019, p. 2).

Em recente matéria publicada na Folha de S. Paulo, o coordenador do subcomitê que trata de temas trabalhistas concernentes a este marco declarou que o principal objetivo do grupo é pensar "mecanismos que possam formalizar prestadores de serviços parceiros das startups (como no modelo adotado pela Uber para trabalhar com motoristas) sem criar barreiras para a atuação dessas companhias", através do "uso de figuras jurídicas já adotadas em outros segmentos, como a do MEI" (Microempreendedor Individual). Segundo o depoimento do coordenador do subcomitê relativo a questões tributárias, a intenção é reduzir o "risco que investidores têm de serem responsabilizados por eventuais passivos trabalhistas e tributários de startups que não deem certo", em vista do fato de serem "negócios arriscados" com "alta probabilidade de não atingir os objetivos propostos" (OLIVEIRA, 2019, p. 2).

Entende-se que esse tipo de edital já atende a este propósito, pois as condições de trabalho instáveis das startups financiadas por este meio tendem a se refletir na pejotização dos quadros funcionais necessários ao desenvolvimento de seus projetos, dentro do mesmo modelo de contratação just in time a que são submetidas, gerando uma rede de trabalhos casuais e sem direitos. Esse encadeamento acontece em vista da modularização da produção, que permite externalizar partes de seus processos para trabalhadores autônomos conforme demanda.

Em síntese, a análise desses editais leva a concluir que as startups têm uma probabilidade muito limitada de se tornarem um grande negócio, sonho de muitas delas, tendendo mais a ampliar processos de pejotização do trabalho que dissimulam vínculos empregatícios. Por se caracterizar como um empreendimento desenvolvido sob incertezas, o retorno de seus projetos só é obtido em caso de viabilidade do escalonamento do seu produto final. Deste modo, a tendência é que nunca saiam da sua condição de microempresa, pois não contam com capital suficiente para a produção em grande escala. Diante disso, restam duas opções para a sua sobrevivência: 1) participar ad aeternum de editais de fomento, e 2) vender seu negócio para uma grande empresa. No segundo caso, ainda que possam receber um bom montante pela venda, os lucros decorrentes do comércio escalonado sempre serão bem maiores.

Considerando que apenas uma grande empresa tem condições de produzir em grande escala, os produtos exitosos resultantes desses editais poderão ser posteriormente adquiridos 
como bens de capital por uma grande firma, enquanto a verba angariada pelas startups selecionadas servirá como renda de trabalho. Ou seja, os frutos da semente serão colhidos pelos investidores, enquanto às startups resta o emprego intermitente.

\section{Considerações finais}

A análise dos editais de fomento às startups procurou desembaraçar as redes de relações casuais de trabalho que fluem das novas formas de investimentos (NFI) ensejadas pela liberalização da economia. O cerne da análise focou na externalização das atividades de inovação à lógica rentista que emana das cadeias globais de valor, facultada pelo caráter modular de suas plataformas tecnológicas. O objetivo foi revelar como o padrão de acumulação de capital sob dominância financeira reestruturou as cadeias produtivas das empresas transnacionais nos moldes de um novo putting-out-system global, com vistas a se apropriar, através do capital financeiro, de ideias com potencialidade de se converterem em negócios lucrativos.

A pesquisa permitiu constatar que os editais analisados funcionam como um meio de conectar encomendas corporativas a trabalhadores autônomos, servindo como um artifício para empregar força de trabalho qualificada sem despesas trabalhistas e disfarçar processos de terceirização dos laboratórios de inovação das grandes marcas pelo emprego do trabalho just in time. Essa estratégia reinventa o salário por peça, ocultando-o sob o estatuto de pessoa jurídica. Com isso, custos laborais são transferidos às startups proponentes, ao mesmo tempo que as deixa permanentemente disponíveis para novos pedidos, reiterando o paradigma do trabalho intermitente e desregulamentado, característico do capitalismo contemporâneo.

Desde essa ótica, as políticas de governança e empreendedorismo inovador revelamse como um artifício para agenciar empregos qualificados baratos para as empresas líderes das CGVs, com subsídios do Estado. Sob a aparência de firmas autônomas, as startups são apresentadas como parceiras dos seus investidores, quando, na verdade, são a esses subordinadas, visto que obedecem às suas demandas de produtividade e às regras sobre como atendê-las. Além de reduzir custos trabalhistas com processos de inovação, essa estratégia ainda permite o compartilhamento das despesas e riscos dos projetos com as startups financiadas. Em tal contexto, o trabalho sem direitos tem servido como moeda de troca para que países de baixa industrialização, como o Brasil, se tornem atrativos às dinâmicas das CGVs.

\section{Referências}

AUDY, Jorge; PIQUÉ, Josep. Dos parques científicos e tecnológicos aos ecossistemas de inovação: desenvolvimento social e econômico na sociedade do conhecimento. Brasília, DF: ANPROTEC, 2016.

CÂMARA DOS DEPUTADOS. Legislação Informatizada. Lei Complementar nº 167, de 24 de abril de 2019. Publicação Original. Brasília, DF, 2019. Disponível em: https://www2.camara.leg.br/legin/fed/leicom/2019/leicomplementar-167-24-abril-2019-788009-publicacaooriginal-157795-pl.html. Acesso em: 15. out. 2019. 
CASTILLO, Juan José. Las fábricas de software en España. Organización y división del trabajo: el trabajo fluido en la sociedad de la información. Política \& Sociedade, Revista de Sociologia Política, Florianópolis, v. 7, n. 3, p. 35-108, 2008.

CASSIOLATO, José Eduardo. Empresas transnacionais e o desenvolvimento tecnológico brasileiro: uma introdução ao artigo "Present international patterns of foreign direct investment: underlying causes and some policy implications for Brazil". Revista de Economia Contemporânea, Rio de Janeiro, v. 17, n. 3, p. 365-375, set./dez. 2013. CHESNAIS, François. Present international patterns of foreign direct investment: underlying causes and some policy implications for Brazil. Revista de Economia Contemporânea, Rio de Janeiro, v. 17, n. 3, p. 377-422, set./ dez. 2013.

CONCEIÇÃO, Cesar Stallbaum.; FEIX, Rodrigo Daniel (org.). Elementos conceituais e referências teóricas para o estudo de aglomerações produtivas locais. Porto Alegre: FEE, 2014. Disponível em: https://www.fee.rs.gov.br/ noticias/e-book-elementos-conceituais-e-referencias-teoricas-para-o-estudo-de-aglomeracoes-produtivas-locais/. Acesso em: 05 jul. 2018.

COWEN, Deborah. The deadly life of logistics: mapping the violence of global trade. Minnesota-EUA: University of Minnesota Press, 2014.

DATASEBRAE. 2019. PIB. Sebrae, 2019. Disponível em: https://datasebrae.com.br/pib/. Acesso em: 12 jan. 2020. FAUSTINO, Cinthia de Azevêdo; GOHR, Cláudia Fabiana. Rendas relacionais como fonte de vantagem competitiva: um estudo de caso em uma empresa calçadista do estado da Paraíba. Revista Gestão Industrial, Curitiba, v. 12, n. 3, p. 1-18, 2016.

FINEP. Edital de Seleção Pública Finep Startup: Programa de Investimento em Startups Inovadoras. Rio de Janeiro, 2017. Disponível em: http://www.finep.gov.br/chamadas-publicas/chamadapublica/614. Acesso em: 10 mai. 2018.

FINEP. Condições operacionais. Rio de Janeiro, 2019. Disponível em: http://www.finep.gov.br/images/a-finep/ Condi\%C3\%A7oes_Operacionais/CondicoesOperacionais.pdf. Acesso em: 20 dez. 2019.

GEREFFI, Gary. International trade and industrial upgrading in theapparel commodity chain. Journal of International Economics, v. 48, n. 1, p. 37-70, 1999.

GUTTMANN, Robert. Uma introdução ao capitalismo dirigido pelas finanças. Novos Estudos CEBRAP, São Paulo, n. 82, p. 11-33, nov. 2008.

HUWS, Uusula. et al. Value chain restructuring in Europe in a global economy. Leuven, Brussels: Katholieke Universiteit Leuven (Higher institute of labour studies), 2009.

ISHIZAKA, Artur Yuiti.; LIZARELLI, Fabiane Letícia. Mensuração da inovação incremental e radical de produtos e processos: uma revisão bibliográfica sistemática. In: ENCONTRO NACIONAL DE ENGRENHARIA DE PRODUÇãO, 36., 2016, João Pessoa. Anais do XXXVI Encontro Anual de Engenharia de Produção. João Pessoa: Universidade Federal da Paraíba, 2016.

KREIN, José Dari. O desmonte dos direitos, as novas configurações do trabalho e o esvaziamento da ação coletiva: consequências da reforma trabalhista. Tempo Social, São Paulo, v. 30, n. 1, p.77-104, 2018. Disponível em: http:// www.scielo.br/scielo.php?script=sci_abstract\&pid=S0103-20702018000100077\&lng=pt\&nrm=iso Acesso em: 28 out. 2019.

KREIN, José Dari.; BIAVASCHI, Magda. Condições e relações de trabalho no segmento das micro e pequenas empresas. In: SANTOS, Anselmo Luís dos; KREIN, José Dari; CALIXTRE, André Bojikian (org.). Micro e pequenas empresas: mercado de trabalho e implicação para o desenvolvimento. Rio de Janeiro: IPEA, p. 113-165, 2012.

LOURES, Hamilton Lopes. Empreendedorismo: uma visão política de seus fundamentos. Negócios em Projeção, Brasília, v. 6, n. 2, p. 93-104, 2015. 
MARTINEZ-ORTIZ, Astrid. O investimento financeiro direto e outras formas de financiamento externo: notas para o exame do período recente na América Latina. 1994. 205 f. Tese (Doutorado em Economia) - Instituto de Economia, Universidade Estadual de Campinas, Campinas, 1994.

MARX, Karl. O salário por peça. In: MARX, Karl. O Capital: crítica da economia política. São Paulo: Abril Cultural, 1984. p. 139-144.

MORO, Suzana Regina; MIGUEL, Paulo Cauchick. Adoção da arquitetura modular na inovação de produtos: uma análise preliminar da literatura. GEPROS. Gestão da Produção, Operações e Sistemas, Bauru, v. 13, n. 2, p. 89$111,2018$.

NARETTO, Nilton; BOTELHO; Marisa dos Reis; MENDONÇA; Maurício. A trajetória das políticas públicas para pequenas e médias empresas no Brasil: do apoio individual ao apoio a empresas articuladas em arranjos produtivos locais. IPEA - Planejamento e Políticas Públicas, Brasília, n. 27, p. 61-115, 2004.

Número de startups no Brasil triplica e passa de 12 mil em 2019. Terra, São Paulo, 02 jan. 2020. Disponível em: https://www.terra.com.br/noticias/dino/numero-de-startups-no-brasil-triplica-e-passa-de-12-mil-em-2019,9b05 05e08a58870029233a531ac91fb74e5pczwl.html. Acesso em: 12 jan. 2020.

OLAVE, Maria Elena León; AMATO NETO, João. Redes de cooperação produtiva: uma estratégia de competitividade e sobrevivência para pequenas e médias empresas. Gestão \& Produção, São Carlos, v. 8, n. 3, p. 289-303, 2001. OLIVEIRA, Filipe. Governo quer marco legal para desburocratizar mercado de startups. Folha de S. Paulo, São Paulo, 12 mar. 2019. Disponível em <https://www1.folha.uol.com.br/mercado/2019/03/governo-quer-marco-legal-para-desburocratizar-mercado-de-startups.shtml>. Acesso em: 10 nov. 2019.

OLIVEIRA, Ivan Tiago Machado; CARNEIRO, Flávio Lyrio; SILVA FILHO. Edison Benedito da (org.). Cadeias globais de valor, políticas públicas e desenvolvimento. Brasília: IPEA, 2017.

O que é uma startup? Sebrae, 2016. Disponível em: https://www.startse.com/noticia/startups/18963/afinal-o-que-e-uma-startup. Acesso em: 12. jan. 2020.

PRADO, Eleutério. Desmedida do valor: crítica da pós-grande indústria. São Paulo: Xamã, 2005.

RONCARATTI, Luanna Sant'Anna. Incentivos a startups no Brasil: os casos do Startup Brasil, InovAtiva e InovApps. In: CAVALCANTE, Pedro. et al. Inovação no setor público: teoria, tendências e casos no Brasil. Brasília: Enap / Ipea, 2017. p. 216-229

SANT ANNA, Eduardo Pimentel. O investimento externo direto no Brasil durante o governo FHC (1995-2002). Revista Observatorio de la Economía Latinoamericana, p. 1-6, 2017.

SANTOS, Anselmo Luís dos; KREIN, José Dari; CALIXTRE, André Bojikian (org.). Micro e pequenas empresas: mercado de trabalho e implicação para o desenvolvimento. Rio de Janeiro: IPEA, 2012. Disponível em: https:// www.ipea.gov.br/portal/index.php?option=com_content\&view=article\&id=16690. Acesso em: 03 mar. 2018.

SCHERER, André Luís Forti. Cadeias de valor e cadeias globais de valor. In: CONCEIÇÃO, Cesar Stallbaum.; FEIX, Rodrigo Daniel (org.). Elementos conceituais e referências teóricas para o estudo de aglomerações produtivas locais. Porto Alegre: FEE, 2014. p. 76-89. Disponível em: https://www.fee.rs.gov.br/noticias/e-book-elementos-conceituais-e-referencias-teoricas-para-o-estudo-de-aglomeracoes-produtivas-locais/. Acesso em: 05 jul. 2018.

SEBRAE, SENAI, SESI. Edital de Inovação para a Indústria 2018: suas ideias nas mãos certas. 2018. Disponível em: https://www.sebrae.com.br/sites/PortalSebrae/ufs/am/artigos/edital-de-inovacao-para-a-industria-2018,cf0c60538c814610VgnVCM1000004c00210aRCRD. Acesso em: 23 mai. 2018.

SEBRAE. Internacionalização das Micro e Pequenas Empresas: oportunidades sugeridas pela experiência internacional (Relatório Final). 2006. Disponível em: http://www.bibliotecas.sebrae.com.br/chronus/ARQUIVOS_ CHRONUS/bds/bds.nsf/E FF1F117F3D42C9183257546007523BF/\$File/NT0003DBDE.pdf. Acesso em: 22 out. 2016. 
SERFATI, Claude. Financial dimensions of transnational corporations, global value chain and technological innovation. Journal of Innovation Economics \& Management, v. 2, n. 2, p. 35-61, 2008.

SPOSITO, Eliseu Silvério; SANTOS, Leandro Bruno. $\mathbf{O}$ capitalismo industrial e as multinacionais brasileiras. São Paulo: Outras Expressões, 2012.

Startups brasileiras apostam em investimento estrangeiro para expandir negócios. Jornal da Globo. Rio de Janeiro, 02 jan. 2020. Disponível em: https://g1.globo.com/google/amp/jornal-da-globo/noticia/2020/01/02/startups-brasileiras-apostam-em-investimento-estrangeiro-para-expandir-negocios.ghtml. Acesso em: 12 jan. 2020.

VILELA, Nágila Giovanna Silva; SANTOS JHUNIOR, Ronaldo de Oliveira. Alianças Estratégicas e Vantagens Competitivas: uma abordagem teórico-empírica sob a ótica da visão baseada em recursos. Journal of Perspectives in Management, v. 2, n. 1, p. 21-31, 2018.

WOLFF, Simone. Cadeias globais de valor no contexto do empreendedorismo e governança urbana: um novo enfoque à questão da precarização do trabalho no capitalismo contemporâneo. In: ANTUNES, Ricardo et al. (org.). Trabajo y capitalismo: relaciones y colisiones sociales. Buenos Aires: Teseo, 2019. p. 219-251

Recebido em: 06/03/2020 Aceito em: 13/04/2020 